\title{
Serotonin Acting via Cyclic AMP Enhances Both the Hyperpolarizing and Depolarizing Phases of Bursting Pacemaker Activity in the Aplysia Neuron R15
}

\author{
Edwin S. Levitan a and Irwin B. Levitan \\ Graduate Department of Biochemistry, Brandeis University, Waltham, Massachusetts 02254
}

Bath application of 5-HT, at concentrations below $10 \mu \mathrm{M}$, enhances the amplitude of the interburst hyperpolarization in the Aplysia bursting pacemaker neuron R15. It is known that 5-HT acts via cyclic AMP to produce this effect by increasing the inwardly rectifying potassium current $\left(I_{\mathrm{A}}\right)$. Here, we report that further elevating the concentration of 5-HT produces an enhancement of the depolarizing phase of the burst cycle that can eventually lead to tonic spiking activity. Voltage-clamp studies reveal that high concentrations of 5-HT continue to increase $I_{R}$ and, in addition enhance a voltage-gated inward current active near the action potential threshold. Pharmacological treatments and ion substitution experiments demonstrate that the inward current increased by high concentrations of 5-HT is a subthreshold calcium current $\left(I_{\mathrm{ca}}\right)$.

The 5-HT-induced increase in $I_{c a}$ is mimicked by bath application of the adenylate cyclase activator forskolin or injection of 8-bromo-cyclic AMP and is potentiated by the phosphodiesterase inhibitor isobutylmethylxanthine. It is concluded that 5-HT, acting via the second messenger cyclic AMP, can increase both potassium and calcium currents in neuron R15. It is also shown that the 5-HT-induced increase in these 2 opposing voltage-gated currents not only produces complex changes in bursting activity, but also dramatically alters $\mathrm{R} 15$ 's response to inhibitory and excitatory stimuli.

The second messenger cyclic AMP mediates the actions of a wide variety of neurotransmitters and hormones on excitable cells (Siegelbaum and Tsien, 1983; Lcvitan, 1985). The actions of cyclic AMP vary between cell type and even within the nervous system of a single animal. In Aplysia, cyclic AMP produces excitatory effects in bag cell, sensory, RB, LB, and medial neurons, while it can inhibit spontaneous bursting in cell R15 (Kaczmarek et al., 1978; Klein and Kandel, 1978; Drummond et al., 1980; Pellmar, 1981; Kehoe, 1985a, b, 1986). The varying effects of cyclic AMP occur because cyclic AMP can modulate different ion channels in different neurons. Cyclic AMP has been shown to modulate 6 types of potassium channels, as well as

Received Jan. 9, 1987; revised Sept. 28, 1987; accepted Sept. 29, 1987

We thank Drs. E. Marder and R. Kramer for their critical comments on an earlier version of the manuscript. This work was supported by NINCDS Grant NS17910 (to I.B.L.).

Correspondence should be addressed to Irwin B. Levitan at the above address.

a Present address: MRC Molecular Neurobiology Unit, University of Cambridge Medical School, Hills Road, Cambridge CB2 2QH, England.

Copyright (C) 1988 Society for Neuroscience $0270-6474 / 88 / 041152-10 \$ 02.00 / 0$ calcium, sodium, and chloride channels in molluscan neurons (Aldenhoff et al., 1983; Ewald and Eckert, 1983; Green and Gillette, 1983; Siegelbaum and Tsien, 1983; Connor and Hock berger, 1984; Hockberger and Connor, 1984; Kaczmarek and Strumwasser, 1984; Kehoe, 1985a, b, 1986; Lotshaw et al., 1986; Strong and Kaczmarek, 1986). In some cells, more than one ion channel is modulated. For example, cyclic AMP decreases 3 distinct potassium currents in Aplysia bag cell neurons to produce excitation (Kaczmarek and Strumwasser, 1984; Strong and Kaczmarek, 1986). In Aplysia medial neurons, 2 potassium currents are decreased and a sodium current increased (Kehoe, 1985a, b, 1986). Finally, in neuron R15, cyclic AMP increases the inwardly rectifying and calcium-activated potassium currents (Benson and Levitan, 1983; Ewald and Eckert, 1983). In all these cases, cyclic AMP produces its effects by modulating several ion channels which tend to act synergistically to produce either depolarization or hyperpolarization.

5-HT, at concentrations below $10 \mu \mathrm{M}$, acts via cyclic AMP to enhance the interburst hyperpolarization produced by the bursting pacemaker Aplysia neuron R15 (Drummond et al., 1980). 5-HT causes this effect by increasing the inwardly (or anomalously) rectifying potassium current $\left(I_{\mathrm{R}}\right)$ (Benson and Levitan, 1983). Here, we report that higher concentrations of 5-HT also enhance the depolarizing phase of bursting pacemaker activity and can eventually lead to tonic spiking activity. This shift from bursting to beating activity is accompanied by an increase in the subthreshold calcium current $\left(I_{\mathrm{Ca}}\right)$. The 5-HT-induced increase in calcium current is shown to be mediated by cyclic AMP. These results demonstrate that 5-HT, acting via a single second messenger, cyclic AMP, can produce complex changes in bursting activity by increasing voltage-gated calcium and potassium currents. It is also shown that this modulation of opposing conductances alters the cell's responsiveness to inhibitory and excitatory stimuli.

\section{Materials and Methods}

Aplysia californica weighing between 100 and $500 \mathrm{gm}$ were obtained from Alacrity Marine Biological Services (Redondo Beach, CA) and maintained at $16^{\circ} \mathrm{C}$. Animals were injected with $50 \%$ of their body weight of $400 \mathrm{mM} \mathrm{MgCl}$. The abdominal ganglion was then removed and the connective tissue sheath overlying cell R 15 dissected away. In preliminary experiments, dissection of the sheath was facilitated by treating the ganglion for $1-10 \mathrm{~min}$ with $0.25 \%$ pronase (Calbiochem). All experiments were reproduced without enzyme treatment.

Cell R15 was identified by its location, pigmentation, and electrical activity (Frazier et al., 1967). R15 was impaled with 1-5 M 2 electrodes containing either 1.5 or $3 \mathrm{M} \mathrm{KCl}$ for measuring voltage and similar electrodes containing $\mathrm{KCl}$ or $0.5 \mathrm{M} \mathrm{K}_{2} \mathrm{SO}_{4}$ for passing current. Iontophoretic injection was performed under voltage clamp (Almost Perfect 
$\mathbf{A}$

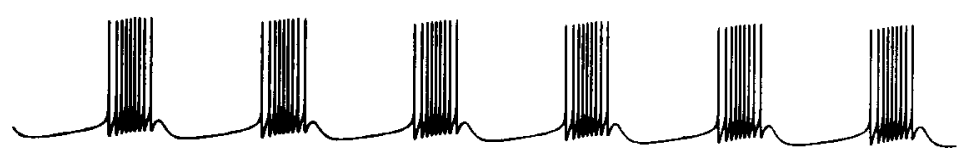

B

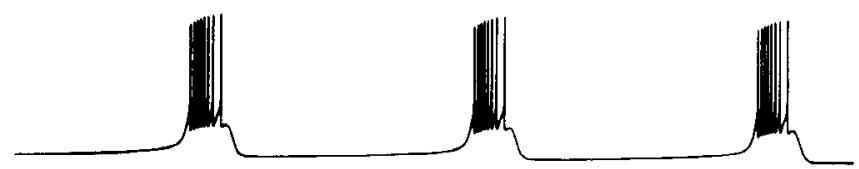

C

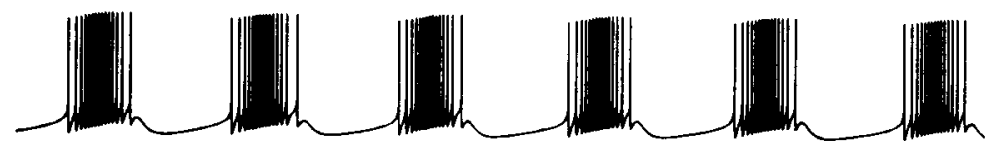

D

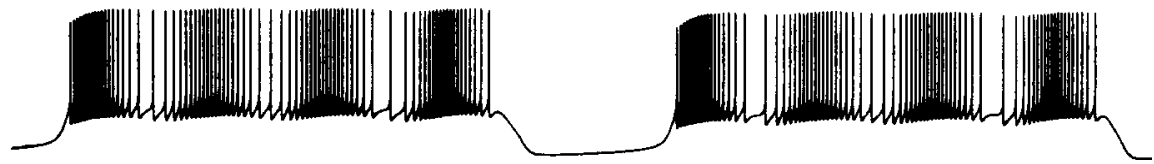

E

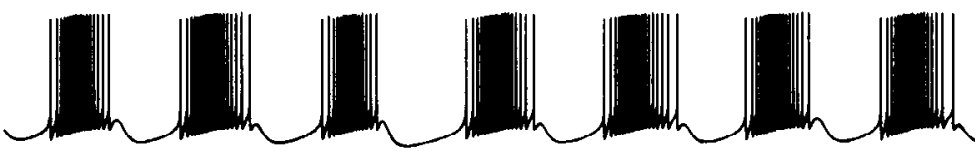

$\mathbf{F}$

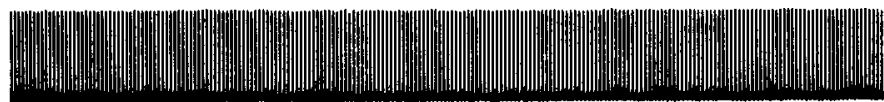

Figure 1. Effects of different concentrations of 5-HT on the bursting activity of cell $\mathrm{R} 15$. $A$, Control activity in $100 \mathrm{~mm} \mathrm{Mg} \mathrm{SW}$. Peak interburst hyperpolarization was $-46 \mathrm{mV}$. $B$, Same as $A$ after $12 \mathrm{~min}$ exposure to $10 \mu \mathrm{M}$ 5-HT. Peak interburst hyperpolarization was $-68 \mathrm{mV}$. C, After washout of 5-HT. D, After 12 min exposure to 50 $\mu \mathrm{M}$ 5-HT. Peak interburst hyperpolar$50 \mathrm{~m} \mathrm{~V}$ ization was $-64 \mathrm{mV} . E$, Control activ$8 \mathrm{~s}$ ity in another cell in ASW. $F$, Same as $E$ after $15 \mathrm{~min}$ exposure to $25 \mu \mathrm{M} 5$-HT.
Electronics) from a third electrode containing $0.75 \mathrm{~m}$ potassium EGTA, $\mathrm{pH} 8,2 \mathrm{M} \mathrm{Cs}_{2} \mathrm{SO}_{4}$, or $0.1 \mathrm{M}$ sodium 8-bromo-cyclic AMP. Iontophoresis of cesium and EGTA simultaneously was accomplished by using a $\mathrm{Cs}_{2} \mathrm{SO}_{4}$ current-passing electrode and an EGTA-filled iontophoresis electrode. Effectiveness of EGTA injections (typically $500 \mathrm{nA}$ for $5 \mathrm{~min}$ ) was verified by testing whether calcium-dependent tail currents and hyperpolarizations were blocked. Cesium was iontophoresed at $500 \mathrm{nA}$ for $14 \mathrm{~min}$.

The ganglion was superfused constantly at $1 \mathrm{ml} / \mathrm{min}$ in a $1 \mathrm{ml}$ bath with artificial seawater (ASW) containing $460 \mathrm{~mm} \mathrm{NaCl}, 10 \mathrm{~mm} \mathrm{KCl}$, $11 \mathrm{mM} \mathrm{CaCl}_{2}, 55 \mathrm{~mm} \mathrm{MgCl}_{2}, 1 \%$ glucose, and $10 \mathrm{~mm}$ HEPES, pH 7.4 . 5-HT was applied for $10 \mathrm{~min}$ unless otherwise stated. To decrease spontaneous synaptic activity, the concentration of $\mathrm{MgCl}_{2}$ was raised to $100 \mathrm{~mm}$ at the expense of $\mathrm{NaCl}(100 \mathrm{~mm} \mathrm{Mg} \mathrm{SW})$. No qualitative differences in the voltage-clamp data were observed in this solution. In other voltage-clamp experiments where maximal block of synaptic activity was desired without completely blocking subthreshold calcium channels, 2 solutions were used. One was similar to ASW except that the concentration of $\mathrm{MgCl}_{2}$ was raised to $230 \mathrm{~mm}$ at the expense of $\mathrm{NaCl}(230 \mathrm{~mm} \mathrm{Mg} \mathrm{SW})$. The other solution, which was similar to that used by Mayeri et al. (1985), contained $430 \mathrm{~mm} \mathrm{NaCl}, 10 \mathrm{~mm} \mathrm{KCl}, 75$ mM MgCl$, 0.3 \mathrm{mM} \mathrm{CaCl}_{2}, 3 \mathrm{~mm} \mathrm{MnCl}_{2}, 1 \%$ glucose, and $10 \mathrm{~mm}$ HEPES, pH 7.4 (0.3 mm Ca SW). The following solution (low Cl SW) was used when a lower external chloride concentration was desired: $392 \mathrm{~mm}$ sodium methylsulfate, $10 \mathrm{mM} \mathrm{KCl}, 50 \mathrm{mM} \mathrm{MgCl}, 50 \mathrm{mM} \mathrm{MgSO}_{4}, 11$ $\mathrm{mm} \mathrm{CaCl}_{2}, 1 \%$ glucose, and $10 \mathrm{~mm}$ HEPES, $\mathrm{pH}$ 7.4. Tetraethylam- monium bromide (TEA), 4-aminopyridine, manganese chloride, and cadmium chloride were added hypertonically. Cobalt was substituted for calcium. Forskolin was added from a stock $30 \mathrm{~mm}$ solution in ethanol. Equivalent exposures of ethanol alone produced no effects. In some experiments, $0.5 \mathrm{~mm}$ hexamethonium bromide was included to block cholinergic synapses on R15.

5-HT (5-hydroxytryptamine creatinine sulfate), dopamine (3-hydroxytyramine hydrochloride), sodium 8 -bromoadenosine- $3^{\prime}, 5^{\prime}$-cyclic phosphate (8-Br-cyclic AMP), 3-isobutyl-1-methylxanthine (IBMX), $N$-2hydroxyethylpiperazine- $N^{\prime}$-2-ethanesulfonic acid (HEPES), and bistrispropane were obtained from Sigma. Forskolin was obtained from Calbiochem. Sodium methylsulfate was obtained from Kodak.

All experiments were replicated a minimum of 3 times, and the data shown are representative. The baseline bursting activity and voltageclamp currents were stable over many hours, and all effects shown were readily reversible upon washing.

\section{Results}

5-HT can enhance both the depolarizing and hyperpolarizing phases of R15's bursting pacemaker activity

Bath application of $10 \mu \mathrm{M} 5$-HT leads to an enhancement of the depth and duration of the interburst hyperpolarization and can sometimes cause cessation of bursting activity in the Aplysia neuron R15 (Drummond et al., 1980). This is due to a cyclic 
$A$

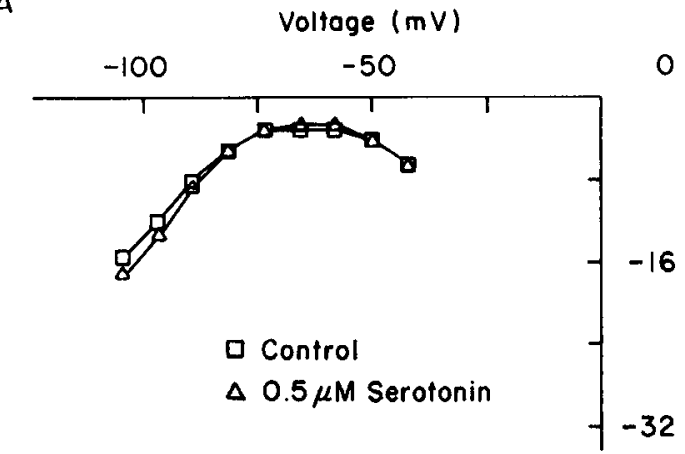

B

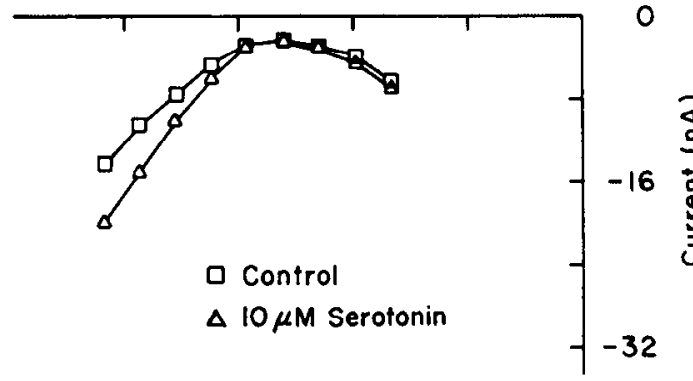

C

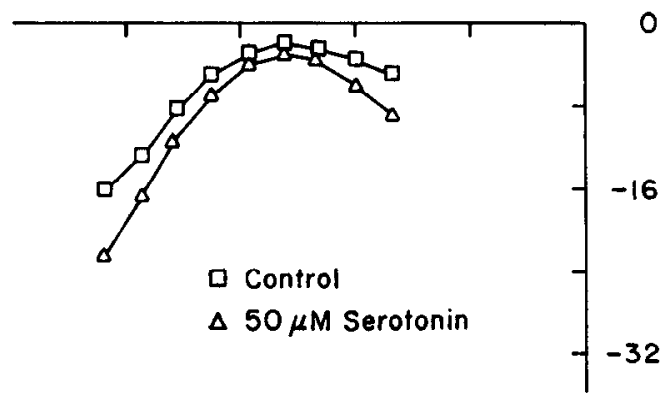

Figure 2. Effects of serotonin (5-HT) on the current versus voltage curve of neuron R15. The effects of $0.5 \mu \mathrm{M}(A), 10 \mu \mathrm{M}(B)$, and $50 \mu \mathrm{M}$ (C) 5-HT on current evoked at the end of 1 sec pulses from a holding potential of $-50 \mathrm{mV}(\square$, control; $\triangle, 5-\mathrm{HT})$. All data from a single cell.

AMP-dependent increase in $I_{\mathrm{R}}$ (Benson and Levitan, 1983). 5-IIT at $500 \mu \mathrm{M}$, on the other hand, has been found to depolarize R15 under current-clamp conditions (Tremblay et al., 1976). We have found that bath application of much lower concentrations of 5-HT (i.e., 25-50 $\mu \mathrm{M}$ ) can produce an enhancement of both the depolarizing and hyperpolarizing phases of the burst cycle. Figure $1 A$ shows the basal bursting activity of $\mathrm{R} 15$ in the presence of elevated magnesium. Upon bath application of 10 $\mu \mathrm{M} 5$-HT an enhancement of the interburst hyperpolarization is seen (Fig. $1 B$ ). After washing out the 5-HT and regaining basal bursting activity (Fig. 1C), $50 \mu \mathrm{M} 5$-HT was applied. Once again, an enhancement of the interburst is seen, this time accompanied by a large increase in the number of action potentials during the depolarizing phase (Fig. $1 D$ ). In normal ASW this depolarizing effect predominates so that the cell eventually ceases bursting and instead spikes tonically at a high frequency (Fig. $1 F$ ). Thus, increasing the concentration of 5-HT can convert its
A

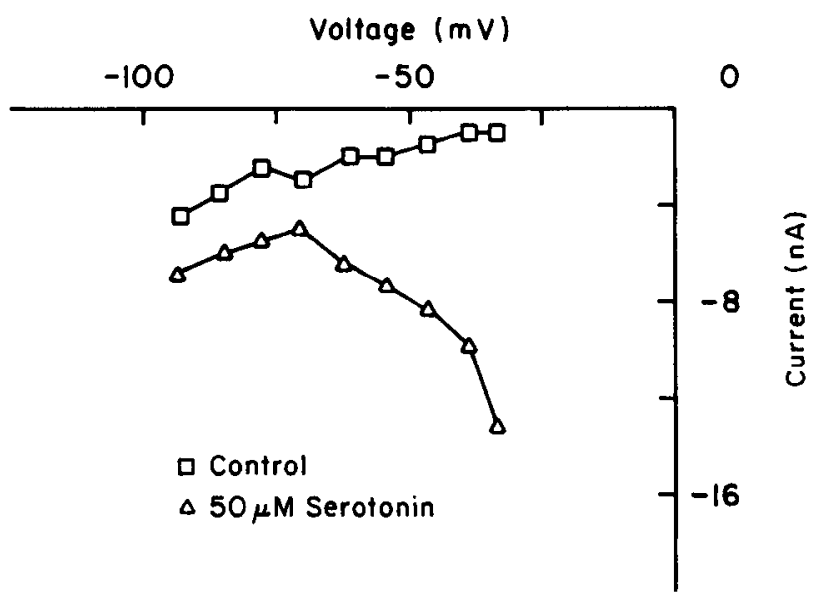

B
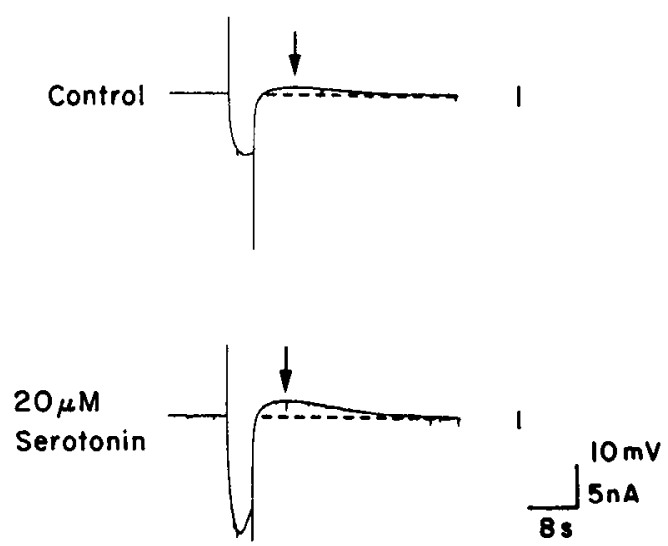

Figure 3. Effect of serotonin (5-HT) on the voltage-gated inward current and the calcium-dependent outward tail current. $A, I_{\mathrm{R}}$ was blocked by reducing external potassium to $2 \mathrm{~mm}$ in $0.3 \mathrm{~mm} \mathrm{Ca} \mathrm{SW}$. Currents were evoked with $2 \mathrm{sec}$ pulses from a holding potential of $-40 \mathrm{mV}: \square$, control; $\triangle$, after $50 \mu \mathrm{M} 5$-HT. $B$, Top trace shows a $10 \mathrm{mV}$ depolarizing voltage pulse from $-45 \mathrm{mV}$; middle trace, the evoked current in the control; bottom trace, evoked current after $20 \mathrm{~min}$ exposure to $20 \mu \mathrm{M}$ 5-HT. Note that 5-HT increases the voltage-gated inward current, as well as the slow tail current (arrows) that is outward relative to the holding current (dotted line).

effect from a predominantly inhibitory one to a predominantly excitatory onc.

\section{5-HT increases the subthreshold voltage-gated calcium and inwardly rectifying potassium currents}

Voltage-clamp experiments were carried out to determine the ionic mechanism by which 5-HT modulates the bursting activity of R15. Bath application of $0.5 \mu \mathrm{M} 5-\mathrm{HT}$ produces an increase in a potassium current that activates with hyperpolarization [the inwardly rectifying potassium current $\left(I_{\mathrm{R}}\right)$; Benson and Levitan, 
1983]. This change in current is most apparent at potentials more hyperpolarized than $-75 \mathrm{mV}$, the potassium equilibrium potential (Fig. $2 A$ ). It is thought that increasing $I_{\mathrm{R}}$ leads to enhancement of the interburst hyperpolarization. Raising the concentration of 5-HT to $2-10 \mu \mathrm{M}$ further increases $I_{\mathrm{R}}$ (Fig. $2 B$ ). In addition, this effect is accompanied by a small increase in the inward current at potentials more positive than $-65 \mathrm{mV}$, the ncgative slope resistance region of the current versus voltage (I$V$ curve (Fig. $2 B$ ). Increasing 5 -HT to $50 \mu \mathrm{M}$ produces little further change in $I_{\mathrm{R}}$, indicating that the excitatory effects of 5-HT are not due to a reversal of the increase in that current. However, an additional increase in inward current is seen at depolarized potentials (Fig. 2C). This effect is also seen under conditions that dramatically lower synaptic activity but that leave calcium currents partially intact (Fig. $3 A$ ), as well as in totally isolated neuron R15 in culture (Lotshaw et al., 1986). Hence, it results from a direct effect of 5-HT on R 15 .

Blocking $I_{\mathrm{R}}$ with either low potassium (Fig. $3 A$ ) or barium (data not shown) reveals that 5 -HT apparently increases 2 additional currents. One component is clearly voltage-gated and displays slow kinetics (Fig. $3 B$ ). It begins to activate between -70 and $-60 \mathrm{mV}$ and increases with depolarization. These characteristics are reminiscent of the subthreshold calcium current. A voltage-independent current is seen at more hyperpolarized potentials (Fig. $3 A$ ) and may be due to activation of a voltage-independent sodium current (Connor and Hockberger, 1984) or to activation of the same voltage-gated current described above but at sites remote from the cell body where voltage cannot be controlled. In favor of the latter interpretation is the finding that the voltage-independent current is not seen when R 15 is maintained in primary ccll culture and processes are removed prior to voltage clamping (D. P. Lotshaw and I. B. Levitan, unpublished observations). Furthermore, agents that reduce the voltage-gated current, such as cobalt, manganese, or dopamine (see below), also reduce the voltage-independent current induced more negative than $-70 \mathrm{mV}$. Thus, it seems likely that 5-HT induces only one type of current in addition to $I_{\mathrm{R}}$. We concentrated on studying the voltage-gated conductance at depolarized potentials which probably is responsible for producing 5-HT's excitatory effect.

The subthreshold inward current active at potentials more positive than $-75 \mathrm{mV}$ has been shown to be due to voltagegated calcium channels that are inactivated by elevated internal calcium (Gorman et al., 1982; Lewis et al., 1984; Adams and Levitan, 1985; Kramer and Zucker, 1985b). Action potentials or depolarizing voltage pulses that allow calcium influx produce a slow outward tail current, which has been shown to be due to calcium-dependent inactivation of resting calcium current normally active at subthreshold voltages (Adams and Levitan, 1985; Kramer and Zucker, 1985b). We found that this outward tail current is increased along with the voltage-gated inward current by 5-HT (arrows in Fig. 3B). This effect is also seen in highmagnesium seawater (data not shown), where synaptic input is minimized (Mayeri et al., 1985). This result is consistent with the hypothesis that 5-HT increases a calcium current $\left(I_{\mathrm{Ca}}\right)$.

In order to test further whether 5-HT increases subthreshold $I_{\text {Ca }}$, calcium currents were blocked with either manganese, cobalt, or cadmium. Shown in Figure $4 A$ is the effect of 5-HT on the slow inward current elicited by depolarization in normal saline in a cesium-loaded cell. As in Figure $3 B, 5-\mathrm{HT}$ nearly doubles the voltage-gated inward current. After washing out the 5-HT, manganese was added. This blocks the voltage-gated in-

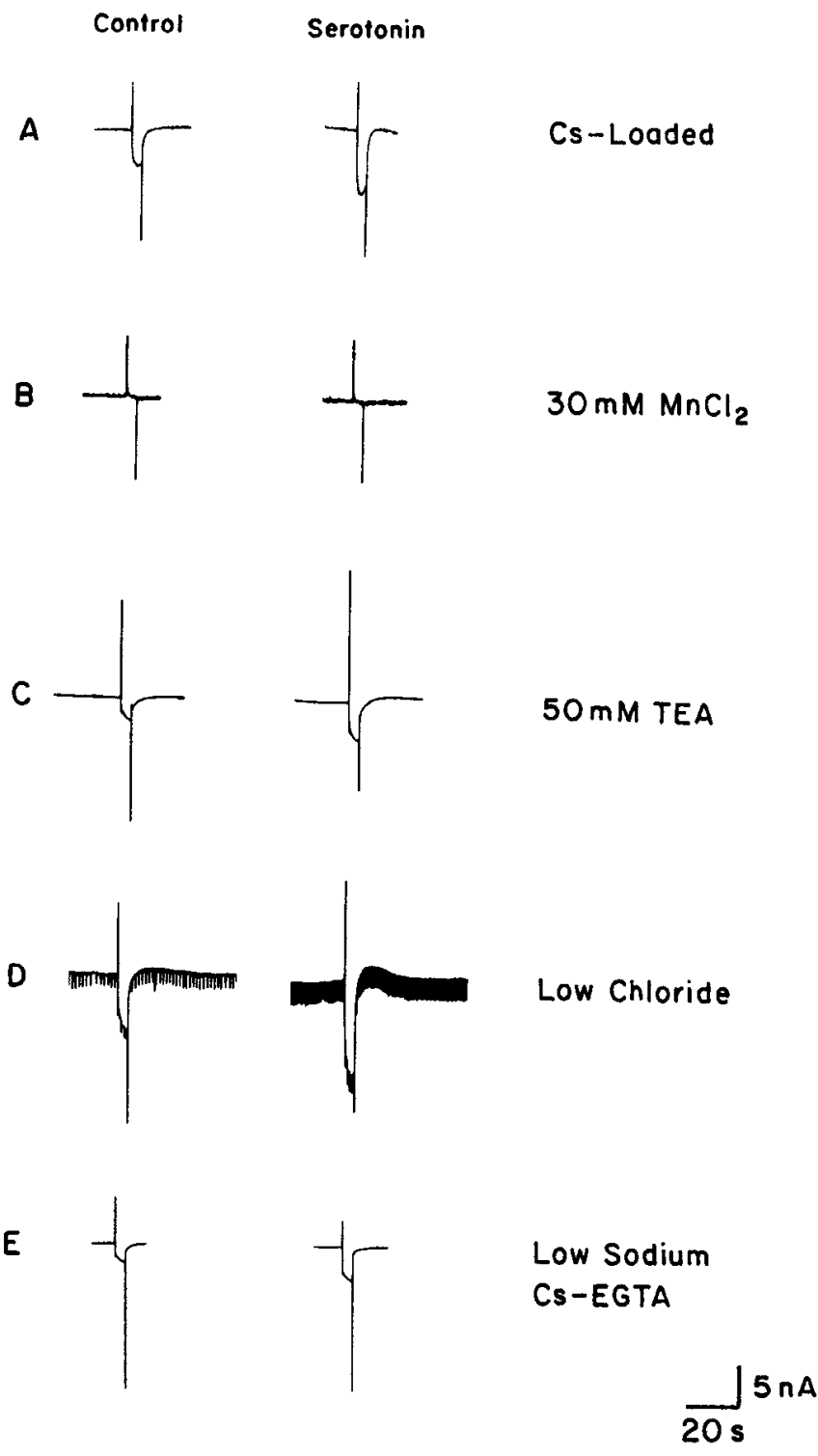

Figure 4. Pharmacology of the serotonin (5-HT)-induced voltage-gated inward current. In each case the current trace at left is the control; at right, after 3-12 min exposure to $50 \mu \mathrm{M}$ 5-HT. $A$, Currents evoked by a $10 \mathrm{mV}$ depolarizing pulse from $-50 \mathrm{mV}$ in a cesium-loaded cell. $B$, Currents in the same cell in the presence of $30 \mathrm{~mm}$ added $\mathrm{MnCl}_{2}$. Similar results were obtained when calcium was replaced with manganese or cobalt. $C$, Currents evoked in another cell by a $5 \mathrm{mV}$ depolarizing pulse from $-24 \mathrm{mV}$ in $230 \mathrm{mM} \mathrm{Mg} \mathrm{SW}$ containing $50 \mathrm{~mm}$ TEA. $D$, Currents evoked in another cell by a $5 \mathrm{mV}$ depolarizing pulse from $-50 \mathrm{mV}$ in low-chloride SW. Downward rapid current deflections are due to a spontaneous cholinergic synaptic input. $E$. After iontophoretically loading R 15 with cesium and EGTA, sodium was lowered to $50 \mathrm{~mm}$ by substitution with bistrispropane. Currents were then evoked by a $7 \mathrm{mV}$ depolarizing pulse from $-36 \mathrm{mV}$ before and after exposure to 5 -HT.

ward current (Fig. 4B, left). Application of 5-HT in the presence of manganese fails to produce any change in current (Fig. $4 B$, right). Similar results were obtained when calcium was replaced with manganese or cobalt in cells not loaded with cesium (data not shown). Addition of $1 \mathrm{~mm}$ cadmium was also found to block the 5-HT induced current (data not shown). These results suggest that 5-HT acts upon $I_{\mathrm{Ca}}$ and/or calcium-activated currents.

5-HT might increase the voltage-gated inward current by de- 


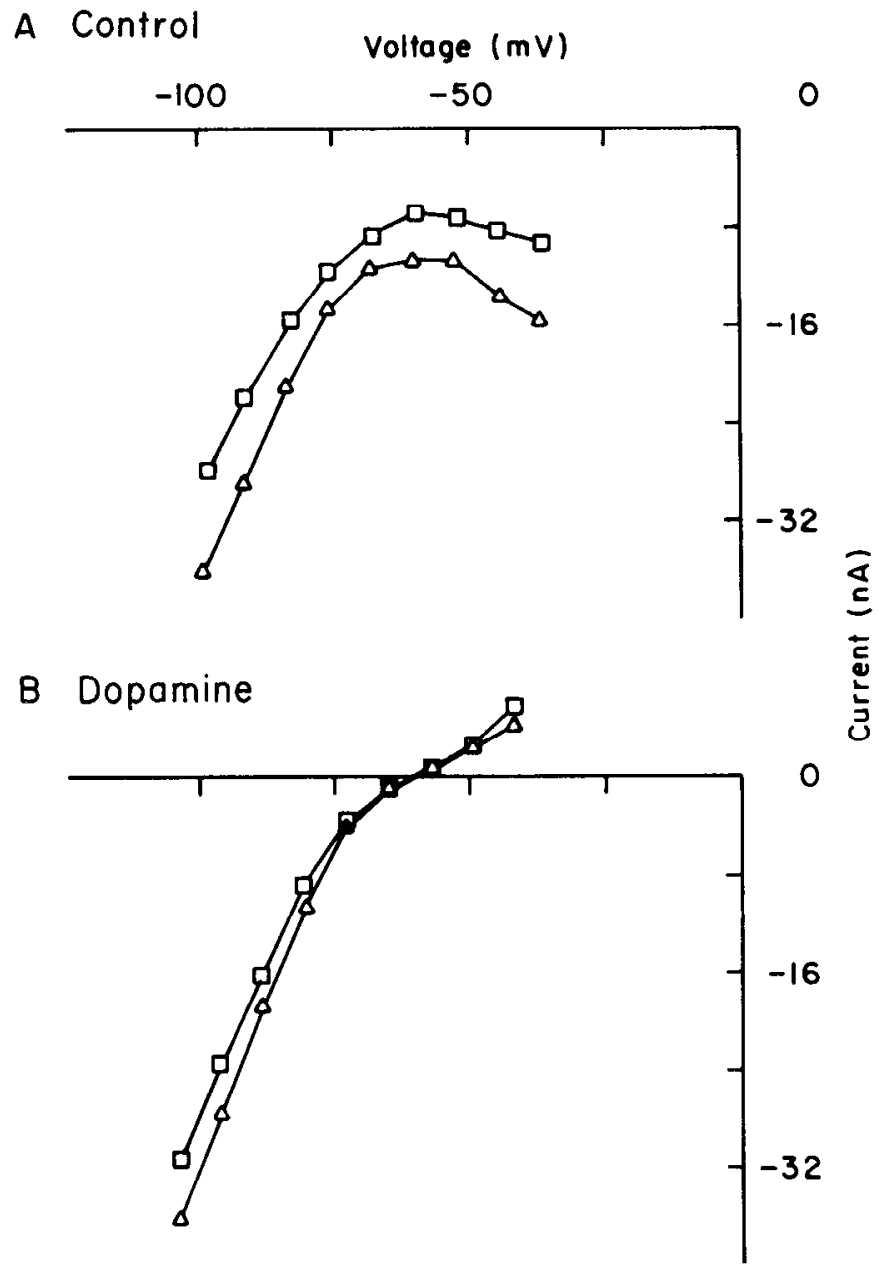

Figure 5. Dopamine attenuates the 5-HT-induced increase in the subthreshold inward current. $A$, Effect of $20 \mu \mathrm{M} 5$-HT on R15's $I-V$ curve; $\square$, control; $\triangle, 5-\mathrm{HT}$. $B$, Effect of 5 -HT in the presence of 250 $\mu \mathrm{M}$ dopamine: $\square$, control; $\triangle, 5-\mathrm{HT}$.

creasing outward potassium currents, although this would produce a decrease rather than the observed enhancement (Fig. $3 B$ ) of the outward tail current. External application of $50 \mathrm{~mm}$ TEA does not block the 5-HT-induced increase in the voltage-gated inward current (Fig. 4C) despite the fact that this concentration is sufficient to block $99 \%$ of the calcium-activated potassium current and $89 \%$ of the delayed rectifying potassium current in R15 (Hermann and Gorman, 1981). Application of 5 mM 4-AP also leaves the 5-HT effect intact (data not shown).

At least 2 potassium currents that are insensitive to TEA and 4-AP but that are blocked by substitution of external calcium with cobalt are known to exist in Aplysia neurons. One of these is a TEA-insensitive, calcium-activated potassium channel. Dietmer and Eckert (1985) reported that iontophoretic loading of cells with cesium blocks this current. Likewise, iontophoretically loading tail sensory neurons with cesium blocks a 5-HTmodulated potassium current that is sensitive to cobalt (Pollock et al., 1985). Cesium loading R 15 to a similar extent, as judged by the measured block of the delayed rectifying potassium current (data not shown), does not block the 5-HT-induced increase in the subthreshold inward current (Fig. $4 A$ ). These results lead us to conclude that 5 -HT does not act by decreasing potassium currents.
5-HT might produce an apparent increase in the subthreshold inward current by decreasing an opposing outward chloride current. In order to test this possibility, external chloride was reduced from 624 to $132 \mathrm{~mm}$ by substituting with methylsulfate, an ion that does not permeate acetylcholine-gated chloride ion channels in Aplysia (Kehoe, 1972). This reduction would be expected to shift the chloride equilibrium potential from approximatcly - $58 \mathrm{mV}$ (Russell and Brown, 1972; Ascher et al., 1976) to about $-19 \mathrm{mV}$, a potential well above the spike threshold. 5-HT still produces a robust increase in the inward current at $-45 \mathrm{mV}$ despite reversal of chloride currents (Fig. $4 D$ ), and thus cannot be acting by decreasing a chloride current.

Yet another possibility is that 5-HT activates a voltage-gated sodium current. Reduction of sodium 9-fold does indeed block 5-HT's effect on the inward current at potentials more positive than $-75 \mathrm{mV}$ (data not shown). However, it has been shown that removal of sodium also blocks the subthreshold calcium current unless the cell is loaded with EGTA and potassium currents are blocked (Gorman et al., 1982). This may occur because sodium removal might allow calcium entry (perhaps by inhibiting sodium-calcium exchange), which in turn leads to inactivation of $I_{\mathrm{Ca}}$ by internal calcium. We have confirmed that iontophoretic loading of R15 with cesium and EGTA, which buffers calcium and blocks potassium channels, dramatically slows the loss of the subthreshold inward current upon reduction of external sodium. Furthermore, under these conditions 5-HT still produces an increase in the subthreshold inward current in low sodium (Fig. $4 E$ ). This, together with the calcium channel blocker experiments, suggests that 5-HT does not activate a sodium current. Furthermore, 5-HT cannot be modulating some intracellular calcium-dependent process since these are blocked following EGTA loading while the 5-HT effect is still intact (Fig. $4 E$ ). These results leave the hypothesis that $5-\mathrm{HT}$ increases $I_{\mathrm{Ca}}$ as the most viable one. A similar conclusion has been reached from studies of cell R 15 maintained in primary culture where pharmacological isolation of calcium currents can be done more rigorously (D. P. Lotshaw and I. B. Levitan, unpublished observations). There it has been shown that 5-HT increases the subthreshold and suprathreshold $I_{\mathrm{Ca}}$ without changing its voltage dependence.

This conclusion is further reinforced by the finding that dopamine, which is known to decrease axonal $I_{\mathrm{Ca}}$ (Lewis et al., 1984), dramatically reduces the 5-HT-induced increase in inward current. Shown in Figure $5 \mathrm{~A}$ are current versus voltage curves from a cell before and after exposure to 5-HT. The 5-HTinduced increases in $I_{\mathrm{R}}$ and $I_{\mathrm{Ca}}$ are evident. Application of a saturating concentration of dopamine blocks the axonal subthreshold $I_{\mathrm{Ca}}$. This is seen in Figure $5 B$ as a loss of the inward current at potentials positive to $-65 \mathrm{mV}$. Application of 5-HT in the continued presence of dopamine still produces some small increase in $I_{\mathrm{Ca}}$ (above $-50 \mathrm{mV}$ ) (Fig. $5 \mathrm{~B}$ ), but this effect is much less than in the absence of dopamine (Fig. 5A). The 5-HTinduced increase in slope conductance below $-75 \mathrm{mV}$, which is due to $I_{\mathrm{R}}$, remains intact in the presence of dopamine. Thus, a transmitter known to decrease $I_{\mathrm{Ca}}$ in $\mathrm{R} 15$ reduces the ability of 5-HT to increase the subthreshold inward current. These data not only support the conclusion that 5-HT modulates calcium channels but also suggest that some of the calcium channels activated by $5-\mathrm{HT}$ are inhibited by dopamine. These channels presumably reside in the axon or axon hillock regions of R15 where dopamine is known to act (Ascher, 1972; Lewis et al., 1984). 
A

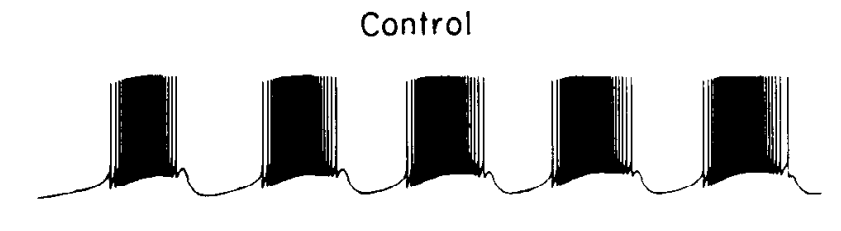

Forskolin

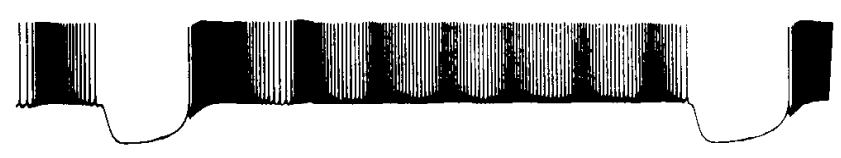

$8 \mathrm{~s}$

B

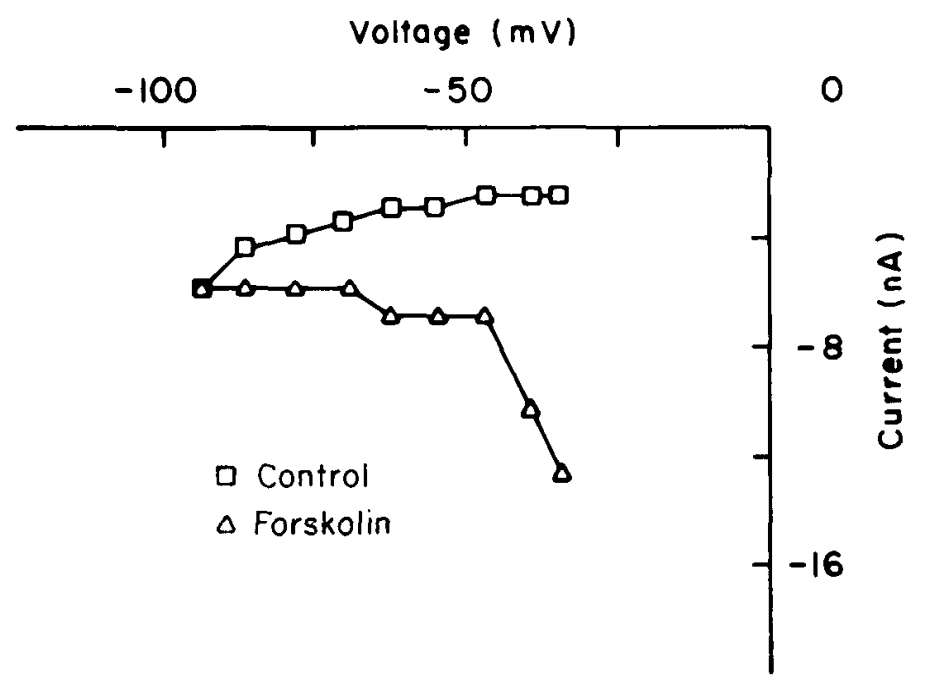

$50 \mathrm{mV}$

Figure 6. Effect of forskolin on bursting activity and on $I_{\mathrm{Ca}}$. $A$. Top trace shows control bursting activity; bottom trace, bursting activity after $30 \mathrm{~min}$ in $80 \mu \mathrm{M}$ forskolin. $B$, Effect of forskolin on the $I-V$ curve in $0.3 \mathrm{~mm}$ Ca SW containing $2 \mathrm{~mm}$ potassium to reduce $I_{\mathrm{R}}: \square$, control; $\Delta$, after 10 min exposure to $90 \mu \mathrm{M}$ forskolin.

\section{5-HT acts via cyclic AMP to increase calcium current in $R 15$}

It has been demonstrated that 5-HT activates adenylate cyclase and elevates cyclic AMP in R15 (Cedar and Schwartz, 1972; Levitan, 1978). This, in turn, mediates 5-HT's effects on $I_{\mathrm{R}}$ (Drummond et al., 1980; Lemos and Levitan, 1984) via activation of cyclic AMP-dependent protein kinase (Adams and Levitan, 1982). A number of experiments were performed to test whether activation of adenylate cyclase is also responsible for the increase in $I_{\mathrm{Ca}}$ seen with higher levels of 5-HT. Forskolin, an activator of adenylate cyclase in many tissues, including $A p l y$ sia neurons (Seamon et al., 1981; Kauer and Kaczmarek, 1985), was bath applied to R15. Enhancement of bursting activity (Fig. $6 A$ ) and increases in $I_{\mathrm{R}}$ (data not shown) and subthreshold $I_{\mathrm{Ca}}$ (Fig. $6 B$ ) were seen even under conditions that minimized synaptic activity. Furthermore, the effects of 5-HT and forskolin occlude each other, suggesting that activating adenylate cyclase modulates the same ion channels as 5-HT (data not shown). The possibility that cyclic AMP could mediate 5-HT's effects on $\mathrm{R} 15$ was further tested by injecting 8-Br-cyclic AMP into R15. Once again, $I_{\mathrm{R}}$ and $I_{\mathrm{Ca}}$ were increased (Fig. 7). These results lead us to conclude that activation of adenylate cyclase and elevation of cyclic AMP can increase subthreshold $I_{\mathrm{Ca}}$ in cell R15.

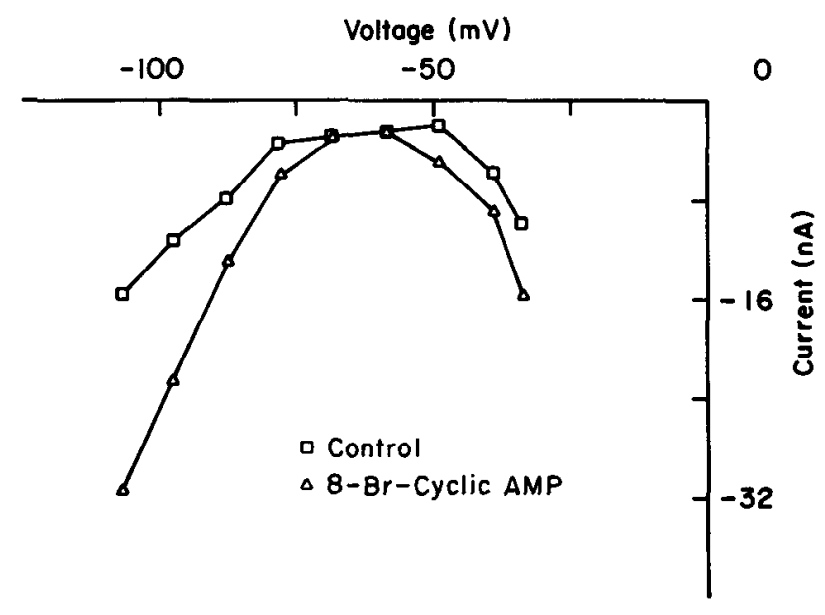

Figure 7. Effect of 8-Br-cyclic AMP injection on the I-V curve of R 15. Currents evoked by $2 \mathrm{sec}$ pulses from $-40 \mathrm{mV}$ before ( $\square$ ) and $4 \mathrm{~min}$ after $(\triangle)$ pressure injection of 8 -Br-cyclic AMP. The injection electrode contained $10 \mathrm{mM} 8$-Br-cyclic AMP. Similar results were obtained with iontophoretic injections. 
A

B
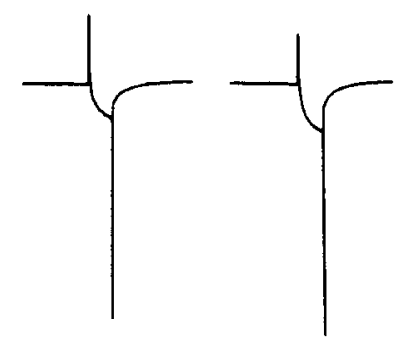

Serotonin

C
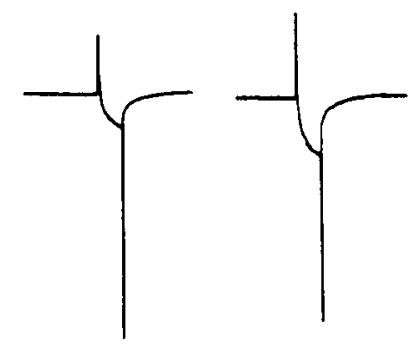

IBMX

$\mathbf{E}$
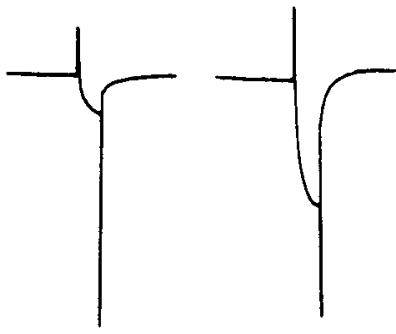

Serotonin + IBMX

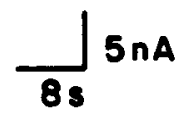

Figure 8. Phosphodiesterase inhibitor potentiates the serotonin (5HT)-induced increase in $I_{\mathrm{ca}}$. In each case the current evoked by an 8 $\mathrm{mV}$ depolarizing voltage pulse from $-48 \mathrm{mV}$ is shown. $A$, Control. $B$, After addition of $1 \mu \mathrm{M}$ 5-HT. $C$, After washing out the 5-HT. $D$, After addition of $0.2 \mathrm{mM}$ IBMX. $E$, After washing out the IBMX. $F$, After exposure to $1 \mu \mathrm{M} 5$-HT together with $0.2 \mathrm{mM}$ IBMX. Note that the increase in current produced by the combined application of 5-HT and IBMX is much larger than the sum of the increases produced by $5-\mathrm{HT}$ and IBMX separately.

It remains possible, however, that $5-\mathrm{HT}$ increases $I_{\mathrm{Ca}}$ by some mechanism independent of cyclic AMP. To address this possibility, we conducted experiments with the phosphodiesterase inhibitor IBMX. Figure 8, $A$ and $B$, shows the effect of $1 \mu \mathrm{M}$ 5-HT on $I_{\mathrm{Ca}}$; Figure 8, $C$ and $D$, shows the effect of bath application of $0.2 \mathrm{mM}$ IBMX. In both cases, only very small increases in $I_{\mathrm{Ca}}$ occurred. Application of 5-HT and IBMX together, however, produced a large increase (Fig. 8, E, F). Thus, a phosphodiesterase inhibitor potentiates the 5 -HT-induced increase in $I_{\mathrm{Ca}}$. This result, taken together with the facts that 5-HT elevates cyclic AMP in R15 and that forskolin and 8-Br-cyclic AMP mimic the effects of 5-HT, leads us to conclude that 5-HT acts via a single second messenger, cyclic AMP, to activate at least 2 ion channels, $I_{\mathrm{R}}$ and $I_{\mathrm{Ca}}$. It may be the balance between these 2 conductances, which have opposing effects on cell excitability, that determines whether a given concentration of 5-HT produces profound inhibition, tonic excitation, or enhancement of both the depolarizing and hyperpolarizing phases of the burst cycle.

\section{R15 responses to inhibitory and excitatory input are altered by} 5-HT

$\mathrm{K} 15$ often does not exhibit robust bursting activity in the intact nervous system; rather, its activity is sometimes found to be dominated by a constant stream of synaptic input (see Adams and Benson, 1985). Therefore, in order to determine the possible physiological importance of modulating 2 voltage-gated conductances with opposing effects on cell excitability, one must determine how 5-HT alters the sensitivity of R15 to synaptic currents. As a preliminary approach to this question, current pulses were applied to R15 in the hope that these would mimic the effects of synaptic currents. While these stimuli are not physiological, passing current directly into R15 insures that any effects seen arise in R15 and not in a presynaptic cell.

Short hyperpolarizing (Fig. 9, $A, B$ ) and depolarizing (Levitan and Levitan, 1988) current pulses produce little effect on the normal bursting activity in R15. Application of $25 \mu \mathrm{M} 5-\mathrm{HT}$, however, not only produces tonic firing activity but also dramatically alters R 15 's response to transient currents. A brief hyperpolarizing current pulse in the presence of excitatory concentrations of 5-HT triggers a long-lasting hyperpolarizing plateau potential (Fig. 9 C). Increasing the magnitude of the current pulse produces almost no change in the depth and duration of the evoked hyperpolarization. These data suggest that the current pulse serves merely to trigger the activation (and/or inactivation) of voltage-gated currents, which, in turn, regeneratively produce the hyperpolarization.

If this is the case, then any outward current, if sufficiently large, may trigger a long hyperpolarizing plateau potential. Depolarizing current pulses that increase spike frequency produce a slow outward current (Levitan and Levitan, 1988), and this outward current can also trigger a long-lasting hyperpolarizing plateau potential in the presence of high concentrations of 5-HT (Fig. $9 E$; the increase in spike frequency is substantial but is not discernible on this time scale).

5-HT can also hyperpolarize and terminate bursting activity in R15 (Drummond et al., 1980), and under these conditions, depolarizing current pulses can trigger a burst of action potentials (Fig. 9D). Once again, this is reminiscent of "plateau potential" cells (Russell and Hartline, 1978; Selverston and Moulins, 1985). These results reinforce the conclusion that 5-HT does not produce simple excitation or inhibition, but rather alters R 15 's bursting activity and sensitivity to hyperpolarizing or depolarizing input. Effectively, 5-HT converts R15 from an autonomous burster into a plateau potential cell. These properties most likely arise because 5-HT increases 2 discrete voltage-gated currents having opposite effects on cell excitability.

\section{Discussion}

We report here that the role of cyclic AMP is more complicated than previously suspected in the bursting pacemaker neuron R15. Application of $10 \mu \mathrm{M} 5-\mathrm{HT}$, a transmitter known to elevate cyclic AMP in R15 (Cedar and Schwartz, 1972), enhances the interburst hyperpolarization of the bursting pacemaker cycle (Drummond et al., 1980). At higher concentrations, 5-HT induces enhancement of both the depolarizing and hyperpolarizing phases of the burst cycle and often produces tonic spiking activity. Voltage-clamp experiments reveal that the increase in $I_{\mathrm{R}}$ underlying the inhibition of bursting at low concentrations 
A

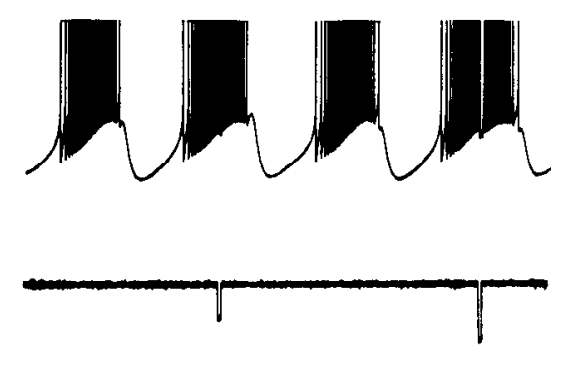

B

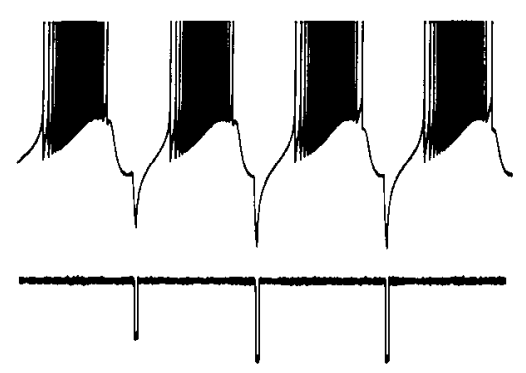

C

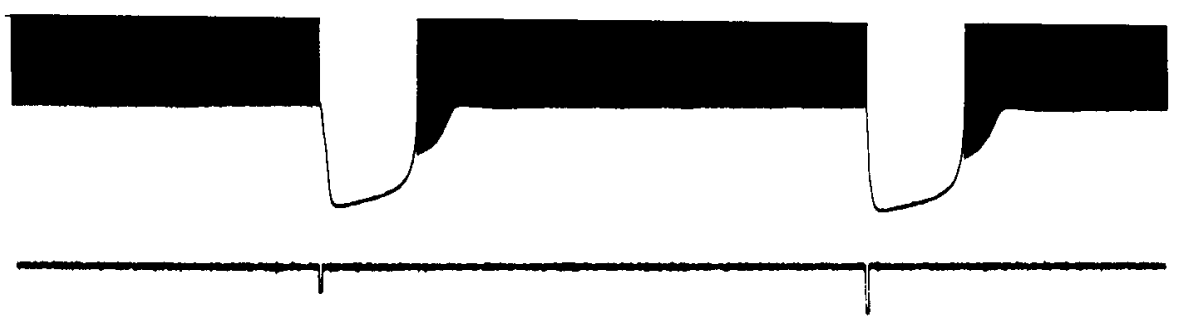

D

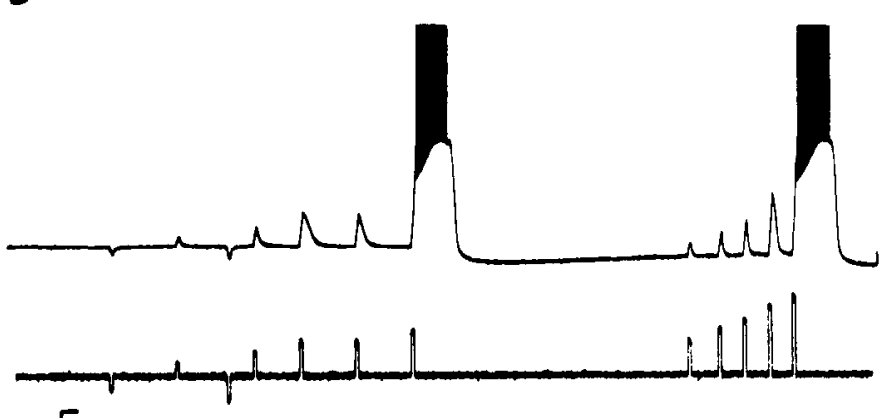

E

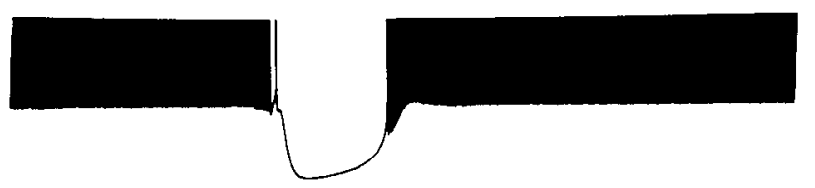

$20 \mathrm{mV}$

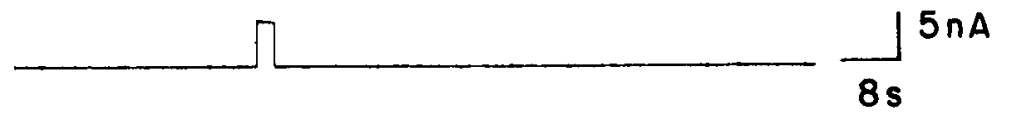

Figure 9. 5-HT alters the effects of hyperpolarizing and depolarizing current pulses on R15's activity. Brief hyperpolarizing current pulses (lower traces) applied to a control cell during a burst $(A)$ or during the interburst $(B)$ produce no long-term changes in R15's bursting activity. $C$, After inducing tonic spiking activity with $25 \mu \mathrm{M} 5$-HT, small hyperpolarizing current pulses trigger longlasting hypcrpolarizations. Increasing the size of the pulse has little effect. $D$, While washing out the 5-HT, this cell hyperpolarized, and during this period depolarizing current pulses can trigger a burst. Bursts cannot be triggered in cells hyperpolarized with dopamine. $E$, In another cell, tonic spiking was induced with $30 \mu \mathrm{M}$ 5-HT. Long-lasting hyperpolarizations could be induced with depolarizing pulses that increase spike frequency. The change in spike frequency is not apparent with the time scale shown. A similar depolarizing pulse has little effect on basal bursting activity (not shown; see Levitan and Levitan, 1988). The tops of the spikes were cut off by the chart recorder in all records. of 5-HT (Benson and Levitan, 1983) remains intact at higher concentrations. Enhancement of the depolarizing phase of the burst cycle, therefore, is not due to a loss of the cyclic AMPmediated increase in $I_{\mathrm{R}}$; rather, 5-HT's depolarizing effect is accompanied by an increase in subthreshold $I_{\mathrm{Ca}}$.

The modulation of $I_{\mathrm{Ca}}$ by 5 -HT is mimicked by either the adenylate cyclase activator forskolin or 8-Br-cyclic AMP, and it is potentiated by the phosphodiesterase inhibitor IBMX. These data, together with the fact that 5-HT increases cyclic AMP in R15 (Cedar and Schwartz, 1972), lead us to conclude that 5-HT's hyperpolarizing and depolarizing effects are both mediated by cyclic AMP. Thus, 5-HT, acting via a single second messenger (cyclic AMP), can produce complex changes in bursting activity by modulating voltage-gated ionic currents $\left(I_{\mathrm{Ca}}\right.$ and $\left.I_{\mathrm{R}}\right)$ with opposing effects on excitability.

The suggestion that cyclic nucleotides can be excitatory in $\mathrm{R} 15$ is not novel. Bath application of a membrane-permeable cyclic AMP analog can produce excitation in R15. However, its effects were attributed to the fact that it indirectly elevates cyclic GMP by inhibiting phosphodiesterases (Levitan et al., 1979). Likewise IBMX has been reported to cause excitatory effects and an increase in the slow inward current, and it was hypothesized that these excitatory effects were also mediated by cyclic GMP, rather than cyclic AMP (Drake and Triestman, 1981). We have found that a membrane-permeable cyclic GMP analog in fact decreases $I_{\mathrm{Ca}}$ (Levitan and Levitan, 1988), and thus the excitatory effects of IBMX are probably mediated by cyclic AMP, not by cyclic GMP. This conclusion is reinforced by the fact that R020-1724, an inhibitor specific for cyclic AMP phosphodiesterase, also increases $I_{\mathrm{R}}$ and $I_{\mathrm{Ca}}$ (unpublished observations).

We have shown here that 5-HT, acting via cyclic AMP, can increase a potassium and a calcium current, and that these 2 currents are modulated at different concentrations of 5-HT. However, when R15s from juvenile Aplysia are maintained in primary cell culture, $1 \mu \mathrm{M} 5-\mathrm{HT}$ is sufficient to produce large increases in both $I_{\mathrm{R}}$ and $I_{\mathrm{Ca}}$. A chloride current, which is evident only when internal chloride is elevated, is also modulated by 
5-HT in these cultured cells (Lotshaw et al., 1986). The fact that $1 \mu_{\mathrm{M}}$ 5-HT activates the different currents equally in cultured cells may be due to a greater sensitivity to $5-\mathrm{HT}$ or, in part, to the fact that cultured cells are completely accessible to 5-HT, whereas in situ R15's soma is exposed while the axon is buried in the neuropil. If 5-HT-sensitive potassium channels are preferentially located on the soma, whereas 5 -HT-sensitive calcium channcls are located on the axon, then the unequal accessibility of the soma and axon in situ might produce an apparent difference in sensitivity to $5-\mathrm{HT}$. Such compartmentation of cyclic AMP-sensitive channels could be tested by locally applying 5-HT to R15's axon and soma.

The question arises of whether the cyclic AMP-induced increases in opposing currents, seen with high concentrations of 5-HT, are physiologically relevant. No known serotonergic neurons synapse on R15, and the levels of circulating 5-HT in Aplysia are not well documented. It is known, however, that excitation of the bag cell neurons leads to secretion of a peptide, egg-laying hormone (ELH), that augments both the hyperpolarizing and depolarizing phases of R15's burst cycle (Branton et al., 1978; Mayeri et al., 1985). We have recently found that bag cell discharge or application of pure ELH increases $I_{\mathrm{R}}$ and $I_{\text {Ca }}$, and that these increases are mediated by an increase in intracellular cyclic AMP in R15 (Levitan et al., 1987). Thus, a cyclic AMP-mediated increase in opposing currents represents a physiological situation.

The effects of ELH suggest a possible reason to modulate opposing currents, which in a normally silent cell makes little intuitive sense. $I_{\mathrm{R}}$ activates regeneratively with hyperpolarization at potentials more negative than the action potential threshold (i.e., $-35 \mathrm{mV}$ ). Therefore, increasing $I_{\mathrm{R}}$ will tend to enhance the interburst hyperpolarization. The subthreshold $I_{\mathrm{Ca}}$ activates regeneratively with depolarization near the action potential threshold, and along with a spike-evoked, $\mathrm{Ca}^{2+}$-activated inward current (Lewis et al., 1984; Adams, 1985; Adams and Levitan, 1985; Kramer and Zucker, 1985a), provides the depolarizing drive to maintain a burst. Since $I_{\mathrm{R}}$ and $I_{\mathrm{Ca}}$ gate at different voltages, and since the regenerative activation of one inactivates the other, increasing both of these voltage-gated currents tends to enhance both the hyperpolarizing and depolarizing phases of the bursting pacemaker cycle. Because bursting activity is thought to be optimal for producing secretion and synaptic release (Gillary and Kennedy, 1969; Dutton and Dyball, 1979), the enhancement of oscillation produced by increasing opposing currents may lead to an enhancement of secretion by $\mathrm{R} 15$, a cell thought to have a neurosecretory function (see Adams and Benson, 1985).

We suggest that another consequence of increasing $I_{\mathrm{Ca}}$ and $I_{\mathrm{R}}$ is to amplify R15's sensitivity to synaptic potentials. Normally, small hyperpolarizing current pulses have little effect on bursting activity. However, 5-HT increases $I_{R}$, which regeneratively activates with hyperpolarization and drives the cell towards the potassium equilibrium potential $(-75 \mathrm{mV})$. Thus, in the presence of 5-HT, there is a rger amou nt of $I_{\mathrm{R}}$ to be activated by hyperpolarization [evoked oy experımentally injecting current (Fig. $9 C$ ) or by increasing spike frequency (Fig. 9E)], and hence long hyperpolarizations are triggered by these small stimuli. These hyperpolarizations finally end because steady-state inactivation of $I_{\mathrm{Ca}}$ is slowly removed at the hyperpolarized potential, causing depolarization; this, in turn, inactivates $I_{\mathrm{R}}$. These results suggest that the 5 -HT-induced increases in 2 voltagegated currents that have opposite effects on cell excitability may enhance R15's sensitivity to excitatory and inhibitory synapses. In fact, the primary physiological effect of elevating cyclic AMP in R 15 may be to convert R 15 from a bursting cell to a plateau potential cell (Russell and Hartline, 1978; Selverston and Moulins, 1985).

It is of interest to compare the effects of dopamine and 5-HT. Like $10 \mu \mathrm{M}$ 5-HT, dopamine enhances the interburst hyperpolarization and can terminate bursting activity ( $\Lambda$ scher, 1972). In contrast to $5-\mathrm{HT}$, dopamine acts by decreasing $I_{\mathrm{Ca}}$ (Lewis et al., 1984). Furthermore, R15 cannot be induced to burst with depolarizing current in the presence of high concentrations of dopamine (Wilson, 1980). Hyperpolarizing concentrations of 5-HT, however, do not prevent the triggering of bursts by depolarizing current pulses (Fig. $9 D$ ). Thus, while 5-HT and dopamine can both inhibit R15's intrinsic bursting activity, they produce opposite effects on R15's responsiveness to excitatory stimuli.

Dopamine can interact with 5-HT by reducing the stimulation of $I_{\mathrm{Ca}}$ by $5-\mathrm{HT}$. This implies that both transmitters can modulate the same calcium channels. It also suggests that 5-HT must elevate cyclic AMP and modulate calcium channels in the axon where dopamine exerts its actions (Ascher, 1972; Lewis et al., 1984). Finally, the fact that dopamine reduces the excitatory effects of 5-HT suggests that small concentrations of dopamine might be sufficient to convert a net excitatory effect of 5-HT and cyclic AMP into a potent inhibitory one. This possibility is of physiological interest since stimulation of the branchial nerve can lead to long-term synaptic inhibition in R15, which appears to consist of a combination of 5-HT-like and dopaminelike effects (Adams et al., 1980).

The actions of cyclic AMP on cell R15 cannot simply be classified as excitatory or inhibitory. This is not wholly surprising since the hasal activity of R 15 is much more complex than that of some other neurons in which the actions of second messengers have been studied. It will be of interest to determine whether the modulation of opposing conductances by a single second messenger will be found to be a typical, rather than a unique, situation in bursting pacemaker neurons. If so, the fact that bursting pacemaker neurons play a central role in controlling neurosecretion and pattern generation (Rapp, 1979; Carpenter, 1982; Selverston and Moulins, 1985) suggests that this phenomenon may be of wide importance in the operation of the nervous system.

\section{References}

Adams, W. B. (1985) Slow depolarizing and hyperpolarizing currents which mediate bursting in Aplysia neurone R 15. J. Physiol. (Lond.) 360: $51-68$.

Adams, W. B., and J. A. Benson (1985) The generation and modulation of endogenous rhythmicity in the Aplysia bursting pacemaker neurone R15. Prog. Biophys. Mol. Biol. 46: $1-49$.

Adams, W. B., and I. B. Levitan (1982) Intracellular injection of protein kinase inhibitor blocks the serotonin-induced increase in $\mathrm{K}^{+}$ conductance in Aplysia neuron R15. Proc. Natl. Acad. Sci. USA 79: 3877-3880.

Adams, W. B., and I. B. Levitan (1985) Voltage and ion dependences of the slow currents which mediate bursting in Aplysia neurone R15. J. Physiol. (Lond.) 360: 69-93.

Adams, W. B., I. Parnas, and I. B. Levitan (1980) Mechanism of longlasting synaptic inhibition in Aplysia neuron R15. J. Neurophysiol. 44: $1148-1160$.

Aldenhoff, J. B., G. Hofmeier, H. D. Lux, and D. Swandulla (1983) Stimulation of sodium influx by cAMP in Helix neurons. Brain Res. 276: 289-296. 
Ascher, P. (1972) Inhibitory and excitatory effects of dopamine and Aplysia neurones. J. Physiol. (Lond.) 225: 173-209.

Ascher, P., D. Kunze, and T. O. Neild (1976) Chloride distribution in Aplysia neurones. J. Physiol. (Lond.) 256: 441-464.

Benson, J. A., and I. B. Levitan (1983) Serotonin increases an anomalously rectifying $\mathrm{K}^{+}$current in the Aplysia neuron R15. Proc. Natl. Acad. Sci. USA 80: 3522-3525.

Branton, W. D., S. Arch, T. Smock, and E. Mayeri (1978) Evidence for mediation of a neuronal interaction by a behaviorally active peptide. Proc. Natl. Acad. Sci. USA 75: 5732-5736.

Carpenter, D. O. (1982) Cellular Pacemakers, Vol. 1, Wiley, New York.

Cedar, H., and J. M. Schwartz (1972) Cyclic AMP in the nervous system of Aplysia californica: Effect of serotonin and dopamine. J. Gen. Physiol. 60: 570-587.

Connor, J. A., and P. Hockberger (1984) A novel membrane sodium current induced by injection of cyclic nucleotides into gastropod neurones. J. Physiol. (Lond.) 354: 139-162.

Dietmer, J., and R. Eckert (1985) Two components of Ca-dependent potassium current in identified neurones of Aplysia californica. Pfluegers Arch. 403: 353-359.

Drake, P. F., and S. N. Triestman (1981) Mechanisms of action of cyclic nucleotides on a bursting pacemaker and silent neuron in Aplysia. Brain Res. 218: 243-254.

Drummond, A. H., J. A. Benson, and I. B. Levitan (1980) Serotonininduced hyperpolarization of an identified Aplysia neuron is mediated by cyclic AMP. Proc. Natl. Acad. Sci. USA 77: 5013-5017.

Dutton, $\Lambda$., and R. E. J. Dyball (1979) Phasic firing enhances vasopressin release from the rat neurohypophysis. J. Physiol. (Lond.) 290: 433-440.

Ewald, D., and R. Eckert (1983) Cyclic AMP enhances calcium-dependent potassium current in Aplysia neurons. Cell. Mol. Neurobiol. 3: 345-353.

Frazier, W. T., E. R. Kandel, I. Kupfermann, R. Waziri, and R. E. Coggeshall (1967) Morphological and functional properties of identified neurons in the abdominal ganglion of Aplysia californica. J. Neurophysiol. 30: 1288-1351.

Gillary, M. L., and D. Kennedy (1969) Neuromuscular effects of impulse pattern in a crustacean motoneuron. J. Neurophysiol. 32: 595606.

Gorman, A. L. F., A. Hermann, and M. V. Thomas (1982) Ionic requirements for membrane oscillations and their dependence on the calcium concentration in a molluscan pace-maker neurone. J. Physiol. (Lond.) 327: 185-217.

Green, D., and R. Gillette (1983) Patch- and voltage-clamp analysis of cyclic AMP-stimulated inward current underlying neurone bursting. Nature 306: 784-785.

Hermann, A., and A. L. F. Gorman (1981) Effects of tetraethylammonium on potassium currents in a molluscan neuron. J. Gen. Physiol. 78: 87-110.

Hockberger, P., and J. A. Connor (1984) Alteration of calcium conductances and outward current by cyclic adenosine monophosphate (cAMP) in neurons of Limax maximus. Cell. Mol. Neurobiol. 4:319338.

Kaczmarek, L. K., and F. Strumwasser (1984) A voltage clamp analysis of currents underlying cAMP-induced membrane modulation in isolated peptidergic neurons of Aplysia. J. Neurophysiol. 52: 340349.

Kaczmarek, L. K., K. Jennings, and F. Strumwasser (1978) Neurotransmitter modulation, phosphodiesterase inhibitor effects, and cyclic AMP correlates of afterdischarge in peptidergic neurons. Proc. Natl. Acad. Sci. USA 75: 5200-5204.

Kauer, J. A., and L. K. Kaczmarek (1985) Peptidergic neurons of Aplysia lose their response to cyclic adenosine $3^{\prime}: 5$ '-monophosphate during prolonged refractory period. J. Neurosci. 5: 1339-1345.

Kehoe, J. S. (1972) The physiological role of three acetylcholine receptors in synaptic transmission in Aplysia. J. Physiol. (Lond.) 225: $147-172$.

Kehoe, J. (1985a) Synaptic block of a transmitter induced potassium conductance in Aplysia neurones. J. Physiol. (Lond.) 369: 399-437.

Kehoe, J. (1985b) Synaptic block of a calcium-activated potassium conductance in Aplysia neurones. J. Physiol. (Lond.) 369: 439-474.

Kehoe, J. (1986) Synaptic correlates of a Na-dependent current induced by cyclic nucleotide (cyclic AMP) in Aplysia neurones. J. Physiol. (Lond.) 377: 34P.
Klein, M., and E. R. Kandel (1978) Presynaptic modulation of voltagedependent $\mathrm{Ca}^{2+}$ current: Mechanism for behavioral sensitization in Aplysia californica. Proc. Natl. Acad. Sci. USA 75: 3512-3516.

Kramer, R. H., and R. S. Zucker (1985a) Calcium-dependent inward current in Aplysia bursting pace-maker neurones. J. Physiol. (Lond.) 362: 107-130.

Kramer, R. H., and R. S. Zucker (1985b) Calcium-induced inactivation of calcium current causes the interburst hyperpolarization of Aplysia bursting pacemaker neurones. J. Physiol. (Lond.) 362: 131160.

Lemos, J. R., and I. B. Levitan (1984) Intracellular injection of guanyl nucleotides alters the serotonin-induced increase in potassium conductance in Aplysia neuron R15. J. Gen. Physiol. 83: 269-285.

Levitan, I. B. (1978) Adenylate cyclase in isolated Helix and Aplysia neuronal cell bodies: Stimulation by serotonin and peptide-containing extract. Brain Res. 154: 404-408.

Levitan, I. B. (1985) Phosphorylation of ion channels. J. Membr. Biol. 87: 177-190.

Levitan, E. S., and I. B. Levitan (1988) A cyclic GMP analog decreases the currents underlying bursting activity in the Aplysia neuron R15. J. Neurosci. 8: 1162-1171.

Levitan, I. B., A. J. Harmar, and W. B. Adams (1979) Synaptic and hormonal modulation of a neuronal oscillator: A search for molecular mechanisms. Exp. Biol. 81:131-151.

Levitan, E. S., R. H. Kramer, and I. B. Levitan (1987) Augmentation of bursting pacemaker activity in Aplysia neuron R 15 by egg-laying hormone is mediated by a cyclic AMP-dependent increase in $\mathrm{Ca}^{2+}$ and $\mathrm{K}^{+}$currents. Proc. Natl. Acad. Sci. USA 84: 6307-6311.

Lewis, D. V., G. B. Evans, and W. A. Wilson (1984) Dopamine reduces slow outward current and calcium influx in burst firing neuron R15 of Aplysia. J. Neurosci. 4: 3014-3020.

Lotshaw, D. P., E. S. Levitan, and I. B. Levitan (1986) Fine tuning of neuronal electrical activity: Modulation of several ion channels by intracellular messengers in a single identified nerve cell. J. Exp. Biol. 124: 307-322.

Mayeri, E., B. S. Rothman, P. H. Brownell, W. D. Branton, and L. Padgett (1985) Nonsynaptic characteristics of neurotransmission mediated by egg-laying hormone in the abdominal ganglion of $A p l y$ sia. J. Neurosci. 5: 2060-2077.

Pellmar, T. C. (1981) Ionic mechanism of a voltage-dependent current elicited by cyclic AMP. Cell Mol. Neurobiol. 1: 87-97.

Pollock, J. D., L. Bernier, and J. S. Camardo (1985) Serotonin and cyclic adenosine $3^{\prime}: 5^{\prime}$-monophosphate modulate the potassium current in tail sensory neurons in the pleural ganglion of Aplysia. J. Neurosci. 5: 1862-1871.

Rapp, P. E. (1979) An atlas of cellular oscillators. J. Exp. Biol. 81: 281-306.

Russell, J. M., and A. M. Brown (1972) Active transport of chloride by the giant neuron of the Aplysia abdominal ganglion. J. Gen. Physiol. 60: 499-518.

Russell, D. F., and D. K. Hartline (1978) Bursting neural networks: A reexamination. Science 200:453-456.

Seamon, K. B., W. Padgett, and J. X. Daly (1981) Forskolin unique diterpene activator of adenylate cyclase in membranes and intact cells. Proc. Natl. Acad. Sci. USA 78: 3363-3367.

Selverston, A. I., and M. Moulins (1985) Oscillatory neural networks. Annu. Rev. Physiol. 47: 29-48.

Siegelbaum, S. A., and R. W. Tsien (1983) Modulation of gated ion channels as a mode of transmitter action. Trends Neurosci. 6: 307313.

Strong, J. A., and L. K. Kaczmarek (1986) Multiple components of delayed potassium current in peptidergic neurons of Aplysia. J. Neurosci. 6: 814-822.

Tremblay, J. P., P. B. J. Woodson, W. T. Schlapfer, and S. H. Barondes (1976) Dopamine, serotonin and related compounds: Presynaptic effects on synaptic depression, frequency facilitation, and post-tetanic potentiation at a synapse in Aplysia californica. Brain Res. 109:6181

Wilson, W. A. (1980) Voltage-sensitive postsynaptic channels. In Molluscan Nerve Cells. From Biophysics to Behaviour, J. Koester and J. H. Byrne, eds., pp. 191-198, Cold Spring Harbor Laboratory, New York. 